Fisheries Research

May 2019, Volume 213 Pages 144-150

https://doi.org/10.1016/i.fishres.2019.01.018

https://archimer.ifremer.fr/doc/00485/59692/

\title{
Age verification of north Atlantic sprat
}

\author{
Moore Claire ${ }^{1,{ }^{*}}$, Lynch Deirdre ${ }^{1}$, Clarke Maurice ${ }^{1}$, Officer Rick ${ }^{2}$, Mills Jane ${ }^{3}$, Defour Jean Louis ${ }^{4}$, \\ Brophy Deirdre ${ }^{2}$
}

${ }^{1}$ Marine Inst, Oranmore, Galway, Ireland.

${ }^{2}$ Galway Mayo Inst Technol, Dublin Rd, Galway, Ireland.

${ }^{3}$ Marine Scotland, Marine Lab, 375 Victoria Rd, Aberdeen AB11 9DB, Scotland.

${ }^{4}$ Inst Francais Rech Exploitat Mer, 150 Ctr Manche Mer Nord, F-62200 Boulogne, France.

*Corresponding author : Claire Moore, email address : claire.moore@marine.ie

\begin{abstract}
:
Sprat is a pelagic species of increasing commercial interest in European waters, yet little is known about its biology or the drivers of its population fluctuations. As a result, the species is currently without an analytical assessment or forecast across much of the North East Atlantic. The objectives of this study were to: verify otolithbased age estimation of sprat; assess the precision, bias and reproducibility of these age estimates; and, determine the age structure of sprat within one North East Atlantic management unit (Celtic Seas ecoregion). Samples were collected over three years $(2011,2013$ \& 2014) from both commercial catches and scientific surveys. Counts of daily increments in otoliths were used to establish when the first annulus was formed. The seasonal development of annuli was validated using marginal increment analysis. Age estimates were found to be both accurate and reproducible with no intra-reader bias and limited inter-reader bias (average coefficient of variation $2.7 \%$ ). The age estimates indicate that the stock is comprised primarily of age 0,1 and 2 year olds. This study has provided previously unavailable information on the biology and age structure of this species which is required to improve assessment and sustainable management of the species.
\end{abstract}

Keywords : Sprat, Age verification, Otolith, Marginal increment analysis, Age structure 


\section{Introduction:}

Age is used in the estimation of many biological parameters including growth, mortality and productivity, which in turn are used to parameterise analytical stock assessment models (Campana, 2001). In particular, errors in the age determination of fast growing pelagic species such as sprat, can greatly influence the estimation of growth curves, resulting in misleading inferences on recruitment and the level of exploitation on the population (Arneri et al., 2011). Therefore, the accurate and precise estimation of age is essential for the sustainable management of a fishery (e.g. Henríqez et al., 2016; Punt et al., 2008; Reeves, 2003).

This study focuses on age verification of European sprat, Sprattus sprattus (Linnaeus, 1758) (hereafter referred to as sprat). Sprat is a fast growing, short-lived, $r$ - selected fish (Peck et al., 2012), that grows to a maximum length of $16 \mathrm{~cm}$ (Whitehead, 1985), with a maximum reported age of 6 years (Chugunova, 1959). This meso-pelagic species has a wide geographical range from Morocco in the south to Norway in the north (Muus \& Nielsen, 1999). There has been a recent increase in fishing effort for sprat within Europe which has been driven by reduced quotas in other fisheries and a growing demand for fishmeal (ICES, 2013a). The rapidly growing market for fishmeal is causing widespread concern about the potential effects on marine biodiversity and on ecosystem integrity and function (Alder \& Pauly, 2006). Mesopelagic fish, such as sprat, form the main constituents of fishmeal but also form an essential link between the lowest trophic levels in a marine ecosystem and the highest trophic levels (Bakun et al., 2009). 
The European sprat fishery remains in a vulnerable position due to lack of biological information, and, in particular, the lack of a validated method for the estimation of age. As a result within the Celtic Seas ecoregion (ICES Divisions $6 \& 7$, excluding 7.e \& 7.d) the stock(s) is considered data limited, and as a result remains unassessed and operates without a Total Allowable Catch (TAC) limit (ICES, 2013a). An important step towards resolving this vulnerability is to validate the stock's age structure and thereby facilitate the development of an analytical stock assessment model. The limited research conducted on age validation of sprat in other regions cannot be assumed to apply to the Celtic Seas ecoregion due to the high variability of sprat growth. Difficulties associated with the age estimation of sprat include the identification of the first winter rings (Torstensen et al., 2004). There is some evidence that sprat otoliths (sagittae) contain false translucent (winter) rings which are formed sub-annually and differ structurally from true annual winter rings (Mosegaard \& Baron, 1999). Although limited work has been conducted on larvae (Alshuth, 1988), no study has been completed on the periodicity of sprat annuli in the north east Atlantic over a single year of growth or age range. Therefore, the objectives of this study were to: verify the methodology of age estimation of sprat; assess the precision, bias and reproducibility of these age estimates; and finally, to use this methodology to verify the age structure of sprat in the large, open, oceanic area to the west of Britain and Ireland.

\section{Materials and methods:}

\subsection{Sampling}

Sprat were collected from the north (ICES Division 6.a), west (7.b) and south (7.g, 7.j) coasts of Ireland (Fig. 1) during 2011, 2013 and 2014. To increase geographical 
and temporal coverage samples were collected opportunistically from both scientific surveys and commercial catches. Survey samples were collected from the RV Celtic Explorer during the international bottom trawl survey using a Grande Overture Verticale (GOV) trawl, the North Sea herring acoustic survey and the Celtic Sea herring survey using a single pelagic midwater trawl. Commercial samples were obtained from five different vessels ranging in length from 4 to 30 meters, all of which worked as twin pair trawlers or seine netters. Samples were frozen on-board for later processing in the laboratory. Samples were obtained for the months of June, August, September, October, November and December, which coincide with the timing of the fishery and surveys. A total of 687 randomly selected sprat were processed. Total lengths $\left(\mathrm{L}_{\mathrm{t}}\right)$ were recorded to the nearest $0.1 \mathrm{~mm}$ and weights were recorded to the nearest $0.01 \mathrm{~g}$. Sex and maturity stage were determined from visual inspection of the gonads using an eight stage sprat maturity key, which was developed from the Marine Institute herring maturity key (Landry \& McQuinn, 1988). Sagittal otoliths were removed using forceps through an incision in the top of the head. Otoliths were gently cleaned with water, air-dried and stored in plastic Eppendorf tubes. To avoid any possible bias only the right otoliths $(n=533)$ were included in this analysis.

\subsection{Age estimation}

Otoliths were aged whole using an Olympus SZX10 binocular microscope, against a black background, with the sulcus facing down under a reflected light source. In line with current sprat ageing practices the birthday was set to January $1^{\text {st }}$ (ICES, 2016; Torstensen et al., 2004). For the purposes of estimating age, one year's growth was defined as a light opaque and an adjoining dark translucent zone. 
One reader estimated the age of the whole sample $(n=533)$ twice, leaving a minimum of three days between each reading. The otoliths were read blind with no prior knowledge of catch location or fish length. Only catch date was provided. From which intra-reader precision was assessed using the $\mathrm{R}$ function agePrecision $\{\mathrm{FSA}\}$ (Ogle, 2016) to determine the average coefficient of variation (ACV) (Chang, 1982):

$$
A C V=100 * \frac{\sum_{j=1}^{n} \frac{s j}{\bar{x} j}}{n}
$$

Where $s$ is the standard deviation of the age estimate and $x$ is the age estimate itself. Inter-reader precision and bias was assessed through an international otolith exchange. Four readers from three different countries, two of whom are experienced sprat age readers, participated in the exchange. Each reader estimated the age of a subset of 60 otoliths using images of the otoliths captured with a Retiga 2000R QImaging camera. A three point grading system for readability was used to determine the quality of the image (ICES, 2013b). The bias in age estimation was assessed using the $\mathrm{R}$ function ageBias $\{\mathrm{FSA}\}$ (Ogle, 2016), which produces age bias plots, age agreement tables and assesses the symmetry of this table using the McNemar test (Evans \& Hoeing, 1998). The significance of any differences in estimates between the expert reader and other readers was assessed using a paired Student's $t$-test with a Holm adjusted $p$-value. Significance is determined by comparing each $p$-value from a one-sample $t$-test adjusted for multiple comparisons to a significance level value of $p$ $=0.05$. 


\subsection{Validation of increment periodicity}

As absolute age cannot be validated under field conditions the age estimates were verified using measurements of inter-annuli distance, marginal increment analysis, and edge type analysis.

Measurement of inter-annuli distances aid in the identification of false winter rings. False rings are sub annual rings that are created during unfavourable conditions (Eltink et al., 2000). This is an issue for sprat in other regions (ICES, 2016b) due to the variability in sprat growth. A randomly selected subset of 124 otoliths were measured along the post-rostrum of the otoliths, where increments were most easily discerned. Variation in zone width due to age and sampling location was analysed using ANOVA.

Marginal increment ratio (MIR) measurements were used to validate the seasonality of annulus deposition. MIR is calculated as:

$$
M I R=\frac{(N E-N L A)}{(N L A-N S A)}
$$

$\mathrm{NE}=$ distance from the nucleus to the edge, $\mathrm{NLA}=$ distance from the nucleus to the last formed annulus, NSA= distance from the nucleus to the second- last formed annulus. Where there was only one annulus the denominator becomes the distance from the nucleus to the annulus (NLA) (Vilizzi \& Walker, 1998). These measurements were all taken along the post-rostrum of a subset of 105 randomly otoliths. An ANOVA was used to determine the significance, magnitude and directionality of the effect of age on MIR. 
When analysed as a function of time, a cyclical pattern emerges in the MIR. At the beginning of the year when the opaque zone is beginning to form, otoliths will have a low MIR value. As the year progresses the MIR value is expected to increase until it reaches a value close to one, at which point annulus formation is complete and the next year of growth is beginning.

The state of growth during the month of capture of each sample was assessed by categorising the edge type of each otolith $(n=533)$ according to its appearance: translucent or opaque. The relative frequency of each edge was examined to confirm the seasonal progression of annulus formation.

\subsection{Verification of the first winter ring:}

Verification of the first winter zone is an essential step in the validation of any age estimation process and to date has not been completed for North Atlantic sprat. Without a correctly defined starting point, age determinations could be consistently wrong by a constant amount (Campana, 2001). Therefore, for this analysis the first translucent winter zone was verified by counting the daily increments present in sagittal otoliths, from the first hatch mark, at around $15 \mu \mathrm{m}$ from the nucleus, which is consistent with previous studies (Alshuth, 1988; Baumann et al., 2008), to the beginning of the first winter zone. The otoliths of eight individual young of the year fish, with a thin translucent zone at the edge, were selected and from these an approximate date of spawning was calculated by subtracting the number of daily increments between the hatch mark and the point of formation of the first translucent zone. An image was first taken of the macro-structure of the otolith from which the distance from the core to the beginning of the first winter zone was measured (Fig 2). This measurement was used as a guideline for comparison with the counts and 
measurements of the daily increments on the sanded otolith. Otoliths were mounted on a glass slide sulcus facing down using a drop of thromplastic glue (Crystalbond ${ }^{\circ}$ ) and then polished on one side using a rotating wheel (Buehler) with a 200mm Akasel polishing cloth and $9 \mu \mathrm{m}$ diamond suspension at $150 \mathrm{~Hz}$ until nucleus to expose the core and the primary growth increments. Otoliths were then imaged (Retiga 2000R QImaging camera) attached using a standard set-up (8 bits per channel, $4800 \times 7200$ pixel frame). In order to capture the full length of the post-rostrum of the otolith, thus enabling counts of all the daily increments multiple images were combined using the tile function in ImagePro version 6.1. Then using ImageJ (Rasband, 2015) with an ObjectJ plugin (Vischer \& Nastase, 2016) the daily increments were counted from the hatch mark at $15 \mu \mathrm{m}$ to the start of the winter zone. The daily increments of each otolith were measured three times by one reader, with a minimum of two days between each reading. In areas where the increments were unreadable the numbers were estimated by interpolation from neighbouring section (Waldron et al., 1991; Waldron \& Kerstan Waldron, 2001). The three counts were averaged. Otoliths were rejected if daily increments were indiscernible in the post-rostral margins, if the primordium was not exposed, if the surface was unreadable or if otolith replicate daily increment counts had an average coefficient of variation greater than $10 \%$.

\subsection{Length at age}

The relationship between length and age is an important component of population dynamics and forms an important input into analytical stock assessment models, allowing managers to estimate growth and mortality. The recorded length at age was summarised and the impact of catch location on length at age was tested using a generalised linear model (glm \{stats $\}$ (R Core Team, 2017)) which was fit assuming a 
Poisson distribution, using a log link function. The impact of catch location on the length of the otolith (from the core to the otolith edge, measured along the rostrum) at age was also tested using a generalised linear model (glm\{stats $\})$ which was fit using a Poisson family distribution and a log link function.

\section{Results}

\subsection{Age estimation}

This sample of north Atlantic sprat was dominated by age 0,1, and 2-year-old fish, with only one 3 -year-old fish $(n=533)$ (Fig. 3). The age estimation process demonstrated high reproducibility with $100 \%$ intra-reader agreement and high inter reader agreement. Inter-reader differences were found to not be significant using a student $t$-test ( $\mathrm{t}(33)=1.44, p=0.16)$. A Chi-square test confirmed that the slight asymmetry (a skew) in the inter-reader age agreement table was not significant $\left(\chi^{2}(1)\right.$ $=2 ; p=0.157$ ) (Table 1$)$, showing that inter-reader error was not significantly influenced by reader experience. The average coefficient of variation was $2.7 \%$ and the overall percentage agreement was $93.3 \%$. Otolith readings were consistently described as high quality images, with an average readability score of $>60 \%$.

\subsection{Verification of annuli:}

Inter-annuli distance decreased as the fish got older. The first opaque zone was three times the width of the second opaque zone $\left(F_{(1,158)}=735.6, p_{\text {_value }}=<0.001, R^{2}=\right.$ 0.823). There was no significant difference in width between the first and second translucent zones $\left(F_{(1,156)}=12.74, p \_v a l u e=<0.001, R^{2}=0.076\right)$. The width of opaque zones also varied significantly between catch locations $\left(F_{(5,155)}=735.6\right.$, p_value $\left.=<0.001, R^{2}=0.847\right)($ Fig. 4). There was no significant difference between 
locations in the width of the translucent zones $\left(F_{(5,152)}=735.6, p_{\text {_value }}=<0.001, R^{2}\right.$ $=0.151)($ Fig 4$)$. No false rings were detected.

In both age- 1 and age- 2 otoliths the MIR increased steadily from June to September (indicating a period of growth) and then stabilized (indicating a period of reduced growth) (Fig. 5). This is corroborated by the edge type analysis which shows that $100 \%$ of otoliths captured between September and December had a translucent edge, indicating the completion of a year's growth (Fig. 6). As only one age-3 fish was found during this study no conclusions can be drawn from its high MIR. However, this high MIR is consistent with the trend of both age-1 and age- 2 fish caught during the same time period (September) (Fig. 6). The proportion of otoliths with an opaque edge in samples from June was $60 \%$, reducing to $15 \%$ in July and to $0 \%$ in September (Fig. 6).

The presumed daily increments were well defined from the nucleus to the otolith edge, but became difficult to discern after 175 days ( \pm 3 SE) on average, ranging from 163 days to 193 days (Table 2). This indicates that the first daily increment forms between April and June (Table 2). The ACV of the repeated readings was $5.34 \%$.

Total length (TL) of fish ranged from $7.2-15.5 \mathrm{~cm}$, with a wide overlap in length between age classes (Fig 7). The mean length at age per age class was: age $0=8.65 \pm$ $0.50 \mathrm{~cm} ;$ age $1=11.47 \pm 1.25 \mathrm{~cm} ;$ age $2=12.46 \pm 1.63 \mathrm{~cm} ;$ and, age $3=13.04 \pm 1.30 \mathrm{~cm}$. Significant correlation was observed between length and age $\left(\chi^{2}(531)=88.082, p=<\right.$ 0.001). The generalized linear model also showed that catch location (north, west, 
south) had a significant impact on the relationship between length and age $\left(\chi^{2}(529)=\right.$ 58.556, $p=<0.001)$. However, there was no significant relationship between catch location and the length of the otolith at age $\left(\chi^{2}(120)=35.092, p=0.2384\right)$.

\section{Discussion:}

This study provides the first verified description of the age structure of sprat within the Celtic Seas ecoregion. Over the three years of this study $(2011,2013 \& 2014)$ the age structure was found to be dominated by just three year classes, age-0 (15\%) , 1 (57\%) and 2 (27\%) (Fig. 3). This truncated age range differs dramatically to the structure of neighbouring sprat management units such as the Skagerrak and Kattegat (ICES Division 3.a) where the population is dominated by age-1 fish (51\% of wanted catch in 2016)(ICES, 2017), and individuals as old as 5 appear annually in the catch (ICES, 2016b). Similarly, the North Sea sprat fishery (ICES Division 4) is dominated by age-1 fish (73\% of wanted catch (ICES, 2017), but age 4 sprat are regularly observed (ICES, 2016b). Within the English Channel (ICES Division 7.d,e) there is no information on the age structure of catches, however four age classes have been identified during the acoustic surveys from which biological samples were collected. These four age classes: $0,1,2$ and 3 , contributed $1.5 \%, 8.9 \%, 70.1 \%$ and $19.4 \%$ to the population by number, respectively (ICES, 2017).

The truncation of age structure has been associated with a number of negative impacts, including lower recruitment (Brunel, 2010; Rouyer et al., 2011; Hixon et al., 2014), reduction in resilience and resistance (Brunel \& Piet, 2013), thus leaving populations vulnerable to environmental fluctuations, including climate change (Ottersen et al., 2006; Planque et al., 2010), and increasing the risk of collapse and 
decreasing their ability to recover (Rouyer et al., 2011). Small pelagic species, such as sprat, could show increased susceptibility to these negative impacts due to their characteristic inter-annual variability in reproductive success and boom-bust cycles. It is unclear from this study what is the driving force behind this truncation. However, sustainable management of this fishery would require continued monitoring of the age structure to determine this is a permeant, or perhaps a transient feature of the boombust cycle of the fishery.

The successful verification of the first winter ring, and validation of the increment periodicity have provided an age estimation tool which could be used to develop an analytical age-based assessment for this economically valuable fishery. However, the truncated age structure identified during the three years of this study would suggest that this species may not be suitable for an analytical age based stock assessment. The steep mortality rates associated with such an age structure would require swift management decisions if they are to keep pace with fluctuations in the fishery's productivity.

The corroboration methods used in this study to identify the cyclical pattern of annulus formation have also provided a number of insights into season trends of this population, which can further inform sampling programs and management decisions. Both the MIR and the edge type analysis demonstrated a period of growth from June to September (Fig. $5 \&$ 6). This pattern of growth coincides with known periods of high plankton productivity in the Celtic Seas ecoregion (ICES, 2016a) that includes a board diversity of prey types including copepods, phytoplankton and meroplankton upon which sprat feed (Falkenhaug \& Dalpadado, 2014). The first annulus was found to form around 175 days ( \pm 3 days SE, ACV 5.34\%) (Table 2), placing the hatch date 
somewhere between April and June which is in agreement other studies, such as the Irish Sea (ICES Division 7.a) where sprat egg production peaked towards the end of May (Coombs et al., 1992). Despite the lack of samples for the first 5 months of the year, the consistent pattern between the three years of data corroborates the observed trends in annulus formation. The authors acknowledge that methods for age corroboration are not equivalent to those for age validation, and that differing methods of age corroboration may reinforce an incorrect age interpretation. Nevertheless, a well-designed corroboratory study can provide valuable support for age validation studies by confirming the accuracy of an age estimate or method (Campana, 2001).

This study revealed a significant variation in otolith opaque zones by catch location, with a variation in the width of the individual annual growth zones (Fig. 4), and a variation in the total length of fish based on catch location. Despite a wide overlap in fish length classes at age (Fig. 7), the length-at-age relationship was significantly affected by catch location $(\chi 2(531)=88.082, \mathrm{p}=<0.001)$. This variation in size-atage may be due to stock separation (Cadrin et al., 2015) or environmental drivers (Peck et al., 2012). Whatever the reason for differences, variations in growth can still translate into temporal variation in productivity and hence create variation in fishery stock yields (Law, 2000). Therefore further research is required on the identification and impacts of these variations in growth. Despite these variations in otolith internal growth and overall fish growth between catch locations there is no evidence of impact on age estimation precision or reproducibility, but it may indicate stock separation within this management unit. 
This work provides the first verified description of the age structure of sprat within the Celtic Seas ecoregion. The age estimation methods applied produced precise, and reproducible results, ensuring that the resulting estimated parameters can be used to develop future stock assessment. This study has changed our perception of the sprat population within this management unit. The revealed truncated age structure indicates that the sprat population in the Celtic Seas ecoregion may be more vulnerable than previously considered, which could predispose the fishery to collapse. Given that sprat in some regions, such as the Baltic, generally do not mature until age2 (Baily 1980) subsequent research on maturation within the Celtic Seas ecoregion is required to ensure that harvest rates reflect the maturity structure of the population structure.

\section{Acknowledgments:}

This work was funded by the Irish Research Council industry partnership scheme. The funding institute was not involved in the study. We thank David Stokes and all the sea-going staff at the Marine Institute for collecting the samples.

\section{References:}

Alder, J. \& Pauly, D, 2006. On the Multiple Uses of Forage Fish: From Ecosystem to Markets. Fisheries Centre Research Reports 14, 109.

Alshuth, S., 1988. Daily Growth Increments on Otoliths of Labratory-Reared Sprat, Sprattus Sprattus L., Larvae. Meeresforsch 32, 23-29.

Arneri, E., Carpi, P., Donato, F. \& Santojanni, A., 2011. Growth in Small Pelagic Fishes and Its Implications in Their Population Dynamics. Biologia Marina Mediterranea 18, 106-113.

Bakun, A., Babcock, E. A. \& Santora, C., 2009. Regulating a Complex Adaptive 
System via Its Wasp-Waist: Grappling with Ecosystem-Based Management of the New England Herring Fishery. ICES Journal of Marine Science 66, 1768-1775.

Baumann, H., Voss, R., Hinrichsen, H.-H., Mohrholz, V., Schmidt, J. O. \& Temming, A., 2008. Investigating the Selective Survival of Summer- over Spring-Born Sprat, Sprattus Sprattus, in the Baltic Sea. Fisheries Research 91, 1-14.

Brunel, T., 2010. Age-Structure-Dependent Recruitment: A Meta-Analysis Applied to Northeast Atlantic Fish Stocks. ICES Journal of Marine Science 67, 1921-1930.

Brunel, T. \& Piet, G., 2013. Is Age Structure a Relevant Criterion for the Health of Fish Stocks? ICES Journal of Marine Science 70, 270-283.

Cadrin, S. X., Kerr, L. A. \& Mariani, S., 2015. Stock Identification Methods : Applications in Fishery Science, 2nd ed. Cadrin, S. X., Kerr, L. A., Mariani, S., eds. London: Elsevier Academic Press.

Campana, S., 2001. Accuracy, Precision and Quality Control in Age Determination, Including a Review of the Use and Abuse of Age Validation Methods. Journal of Fish Biology 59, 197-242.

Chang, W. Y. B., 1982. A Statistical Method for Evaluating the Reproducibility of Age Determination. Canadian Journal of Fisheries and Aquatic Sciences 39, 12081210.

Chugunova, N. I., 1959. Age and Growth Studies in Fish. A Systematic Guide for Ichthyologists. Moskva: Izdatel'stvo Akademii Nauk SSSR.

Coombs, S. H., Nichols, J. H., Conway, D. V. P., Milligan, S. \& Halliday, N. C., 1992. Food Availability for Sprat Larvae in the Irish Sea. Journal of Marine Biological Association U.K. 72, 821-834.

Eltink, A. T. G. ., Newton, a W., Morgado, C. \& Modin, J., 2000. Guidlines and Tools for Age Reading Compariisons. 
Evans, G. T. \& Hoeing, J. M., 1998. Testing and Viewing Symmetry in Contingency Tables, with Application to Readers of Fish Ages. Biometrics 620-629.

Falkenhaug, T. \& Dalpadado, P., 2014. Diet Composition and Food Selectivity of Sprat ( Sprattus Sprattus ) in Hardangerfjord, Norway. Marine Biology Research 10, 203-215.

Henríqez, V., Licandeo, R., Cubillos, L. A. \& Cox, S. P., 2016. Interactions between Ageing Error and Selectivity in Statistical Catch-at-Age Models: Simulations and Implications for Assessment of the Chilean Patagonian Toothfish Fisher. ICES Journal of Marine Science 73, 1074-1090.

Hixon, M. a, Johnson, D. W. \& Sogard, S. M., 2014. Structure in Fishery Populations. ICES Journal of Marine Science 71, 2171-2185.

ICES, 2013a. Report of the Benchmark Workshop on Sprat Stocks (WKSPRAT).

ICES CM 2013/ACOM:, 220.

ICES, 2013b. Report of the Second Workshop of National Age Readings

Coordinators ( WKNARC2 ). ICES CM 2013/ACOM:52.

ICES, 2016a) Celtic Seas Ecoregion - Ecosystem Overview.

ICES, 2016b. Report of the Workshop on Age Estimation of Sprat ( Sprattus Sprattus) ( WKARSPRAT ).

ICES, 2017. Herring Assessment Working Group Report for the Area South of 62

Deg N ( HAWG ). ICES CM 2017/ACOM:07.

Landry, J. \& McQuinn, I. H., 1988. Guide d'identification Microscopique et Macroscopque Des Stades de Maturité Sexuelle Du Hareng de l'Atlantique (Clupea Harengus Harengus L.). Canadian technical report of fisheries and aquatic science $1655,71$.

Law, R., 2000. Fishing, Selection , and Phenotypic Evolution. 659-668. 
Mosegaard, H. \& Baron, P. R., 1999. Validation of Annual Rings by Primary

Increment Characteristics in Herring and Sprat Sagitta Otoliths. Lecture at EFAN

Meeting, Notes Can Be Found at www.efan.no .

Muus, B. J. \& Nielsen, J. G., 1999. Seafish. Oxford: Blackwell Science.

Ogle, D. H., 2016. FSA: Fisheries Stock Analysis. R package 2016.

Ottersen, G., Hjermann, D. O. \& Stenseth, N. C., 2006. Changes in Spawning Stock

Structure Strengthen the Link between Climate and Recruitment in a Heavily Fished

Cod (Gadus Morhua) Stock. Fisheries Oceanography 15, 230-243.

Peck, M. A., Baumann, H., Bernreuther, M., Clemmesen, C., Herrmann, J. P., Haslob,

H., Huwer, B., Kanstinger, P., Köster, F. W., Petereit, C., et al., 2012. The

Ecophysiology of Sprattus Sprattus in the Baltic and North Seas. Progress in

Oceanography 103, 42-57.

Planque, B., Fromentin, J. M., Cury, P., Drinkwater, K. F., Jennings, S., Perry, R. I. \&

Kifani, S., 2010. How Does Fishing Alter Marine Populations and Ecosystems

Sensitivity to Climate? Journal of Marine Systems 79, 403-417.

Punt, A. E., Smith, D. C., KrusicGolub, K. \& Robertson, S., 2008. Quantifying Age-

Reading Error for Use in Fisheries Stock Assessments, with Application to Species in

Australia's Southern and Eastern Scalefish and Shark Fishery. Canadian Journal of

Fisheries and Aquatic Sciences 65, 1991-2005.

R Core Team., 2017. R: A Language and Environment for Statistical Computing. R

Foundation for Statistical Computing, Vienna, Austria., 2017.

Rasband, W., 2015. ImageJ. Marylan, USA: U. S. National Institutes of Health,

Bethesda, 2015.

Reeves, S. A., 2003. A Simulation Study of the Implications of Age-Reading Errors for Stock Assessment and Managment Advice. ICES Journal of Marine Science 314 
328.

Rouyer, T., Ottersen, G., Durant, J. M., Hidalgo, M., Hjermann, D., Persson, J., Stige,

L. C. \& Stenseth, N. C., 2011. Shifting Dynamic Forces in Fish Stock Fluctuations

Triggered by Age Truncation? Global Change Biology 17, 3046-3057.

Torstensen, E., Eltink, A. T. G. ., Casini, M., McCurdy, W. J. \& Clausen, L. W., 2004. Report of the Work Shop on Age Estimation of Sprat. Arendal, Norway.

Vilizzi, L. \& Walker, K. F., 1998. Age Profile of Carp (Cyprinus Carpio L.) in Lake

Cresent, Tasmania. Papers and Proceedings of the Royal Society of Tasmania 132.

Vischer, N. \& Nastase, S., 2016. ObjectJ. Univeristy Of Amsterdam 2016.

Waldron, M. E. \& Kerstan Waldron, M., 2001. Age Validation in Horse Mackerel

(Trachurus Trachurus) Otoliths. ICES Journal of Marine Science - ICES Journal of

Marine Science 58, 806-813.

Waldron, M. E., Prosch, R. M. \& Armstrong, M. J., 1991. Growth of Juvenile Round Herring Etrumeus Whiteheadi in the Benguela System. South African Journal of Marine Science 10, 83-89.

Whitehead, P. J. P., 1985. Clupeoid Fishes of the World (Suborder Clupeioidei). An Annotated and Illustrated Catalogue of the Herrings, Sardines, Pilchards, Sprats, Shads, Anchovies and Wolf-Herrings. FAO Fisheries Synopsis 7, 303. 
Table 1: Summary of individual age agreement tables. This table compares the final age estimation of each reader to that of the expert reader. Only two readers were in disagreement for two otoliths within the exchange.

\begin{tabular}{lcccc} 
& \multicolumn{5}{c}{ Reader 1 (expert) } \\
\hline & Age & $\mathbf{0}$ & $\mathbf{1}$ & $\mathbf{2}$ \\
\hline \multirow{2}{*}{ Reader 2 } & $\mathbf{0}$ & 2 & - & - \\
& $\mathbf{1}$ & - & 33 & - \\
& $\mathbf{2}$ & - & - & 25 \\
\hline \multirow{2}{*}{ Reader 3 } & $\mathbf{0}$ & 2 & - & - \\
& $\mathbf{1}$ & - & 31 & - \\
& $\mathbf{2}$ & - & 2 & 25 \\
\hline \multirow{2}{*}{ Reader 4 } & $\mathbf{0}$ & 2 & - & - \\
& $\mathbf{1}$ & - & 31 & - \\
& $\mathbf{2}$ & - & 2 & 25 \\
\hline
\end{tabular}


Table 2: Summary of the daily increment measurements for each fish; average was calculated from the mean of the three replicates for each fish. Summary of back calculated hatch date for 6 fish based on daily increment counts (DIC). Indicating that the first daily increment is laid down between April and June.

$\begin{array}{cccc}\begin{array}{c}\text { Fish } \\ \text { ID }\end{array} & \begin{array}{c}\text { Date of } \\ \text { Capture }\end{array} & \begin{array}{c}\text { Date of } \\ \text { first DI }\end{array} & \text { Daily Increments } \\ 1 & 04 / 10 / 2013 & 19 / 04 / 2013 & 168 \pm 14(152-180) \\ 2 & 29 / 11 / 2013 & 18 / 06 / 2013 & 163 \pm 1(162-164) \\ 3 & 07 / 11 / 2013 & 10 / 05 / 2013 & 181 \pm 10(174-192) \\ 4 & 07 / 11 / 2013 & 28 / 04 / 2013 & 193 \pm 8(184-199) \\ 5 & 07 / 11 / 2013 & 18 / 05 / 2013 & 173 \pm 17(157-190) \\ 6 & 07 / 11 / 2013 & 13 / 05 / 2013 & 178 \pm 7(171-184)\end{array}$




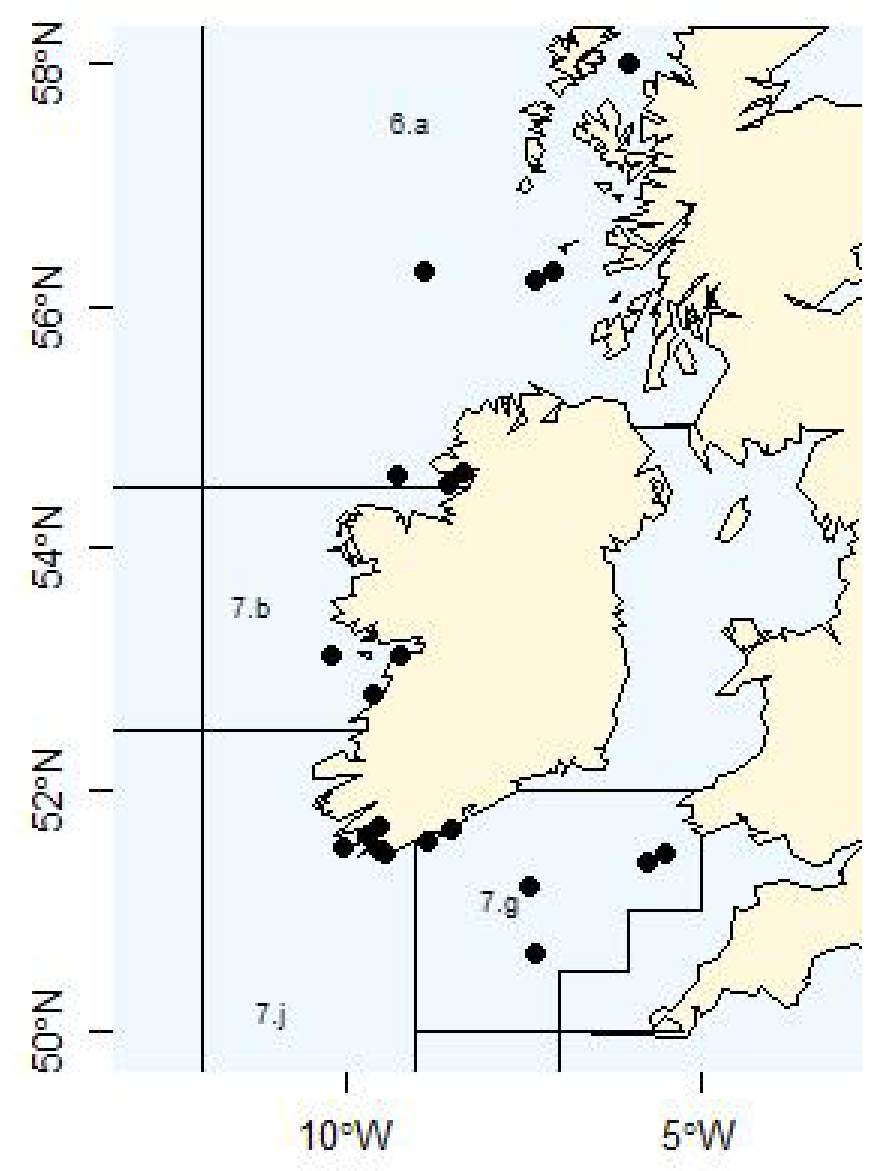

Fig 1: Map of sampling area (ICES Division 6.a, 7.b, 7.j and 7.g). Black points indicate the location of hauls sampled during 2011, 2013 and 2014. The results of this analysis are discussed in terms of three geographical sections of this area: north (6.a), west (7.b) and south (7.g and 7.j). 


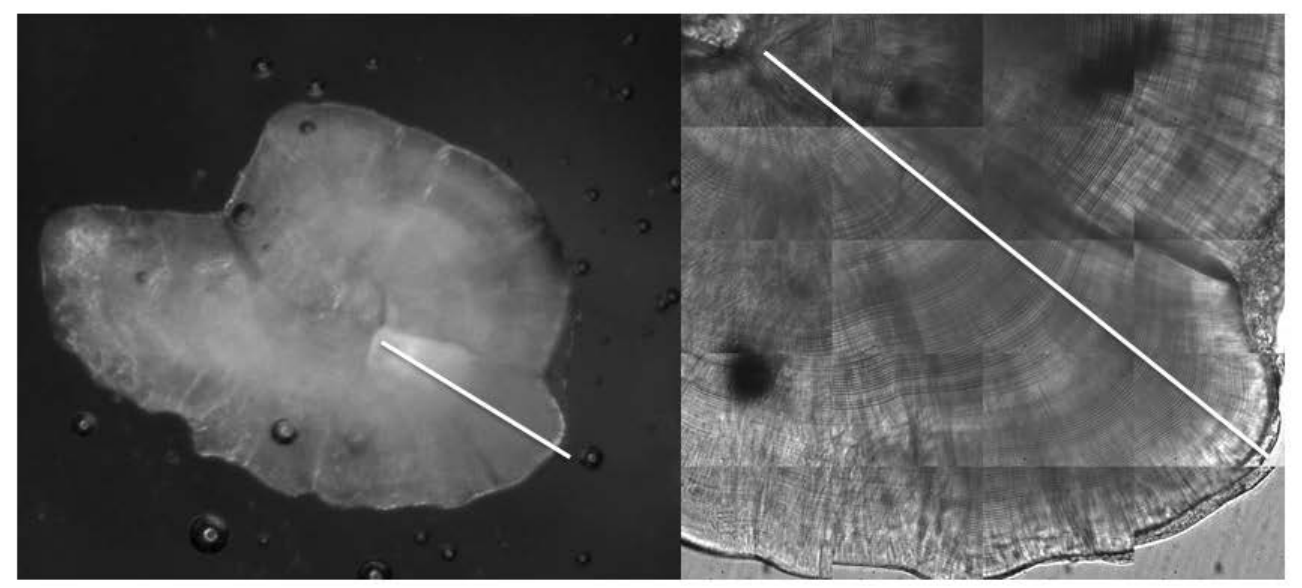

Fig. 2 Shows the macro (left) and micro (right) formation of annual and daily increments. The red line denotes the trajectory along which measurements and daily increment counts were made. 


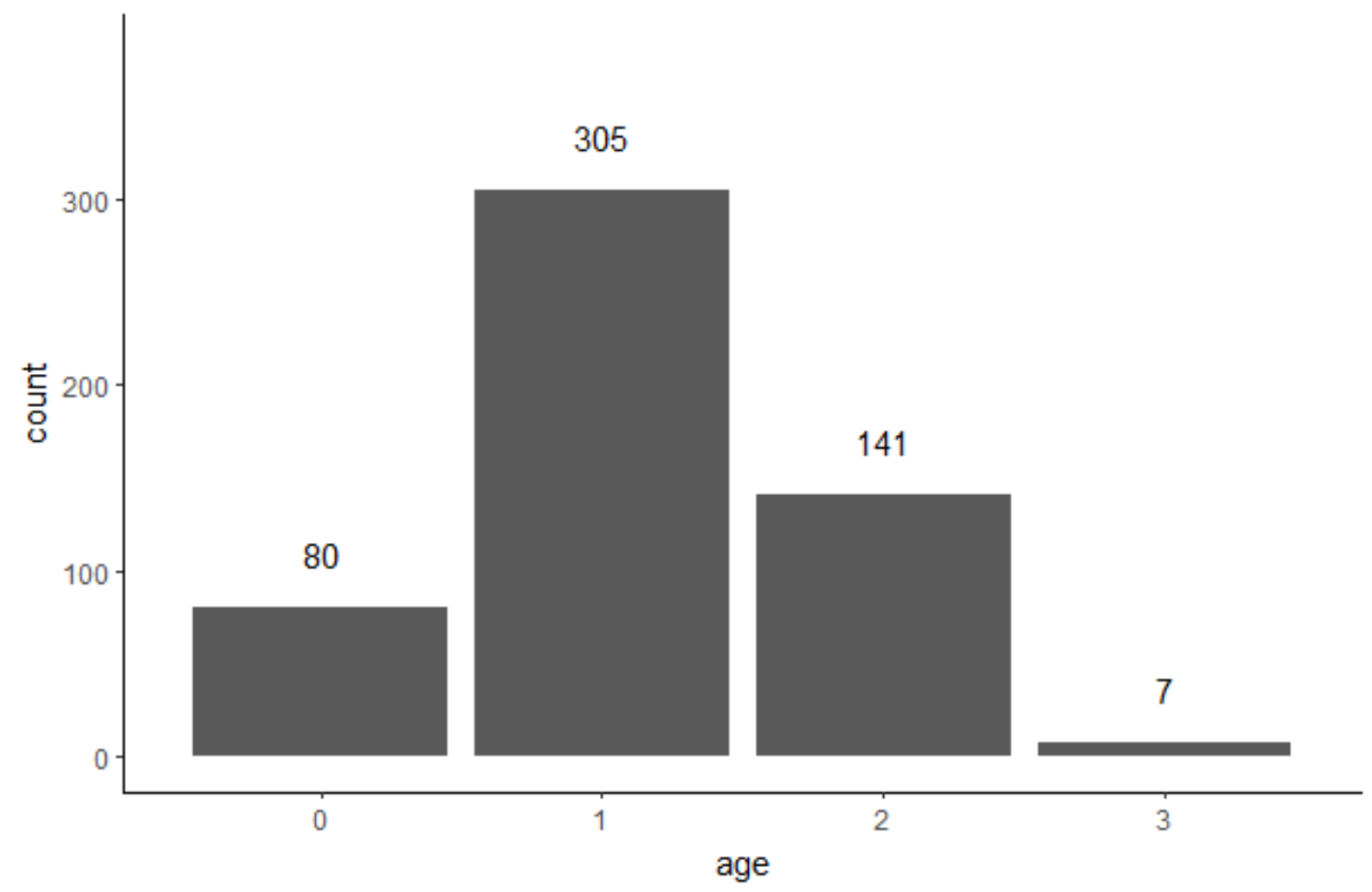

Fig. 3 The frequency of estimated age of the sample $(n=533)$, age sample numbers indicated at the top of the bars. 

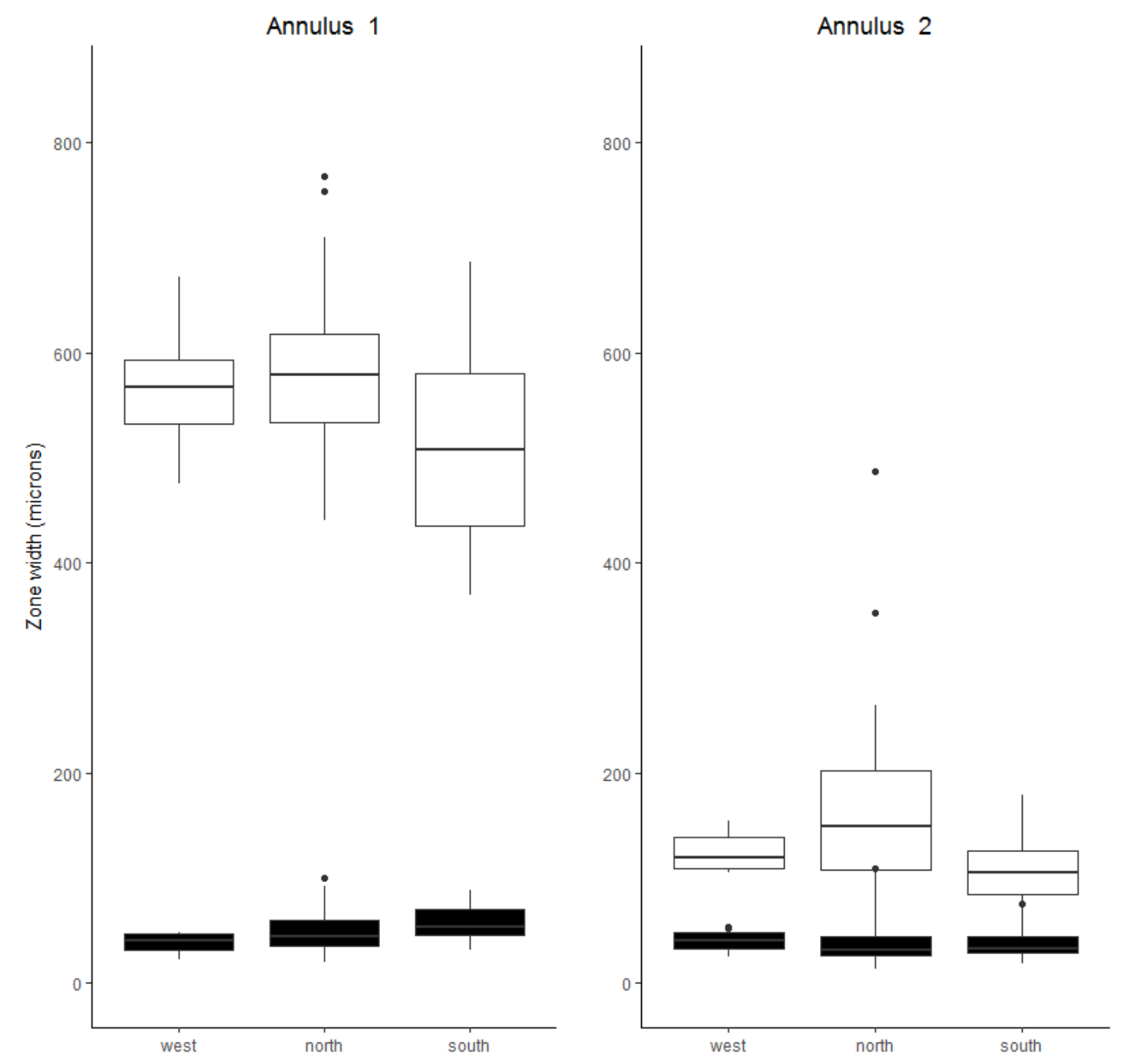

Fig. 4: Trends in the width of opaque and transparent zones of the first (left) and the second (right) annulus. A significant difference was found in the width of opaque zones due to catch location, but not in the width of the transparent zones. 
Age 1

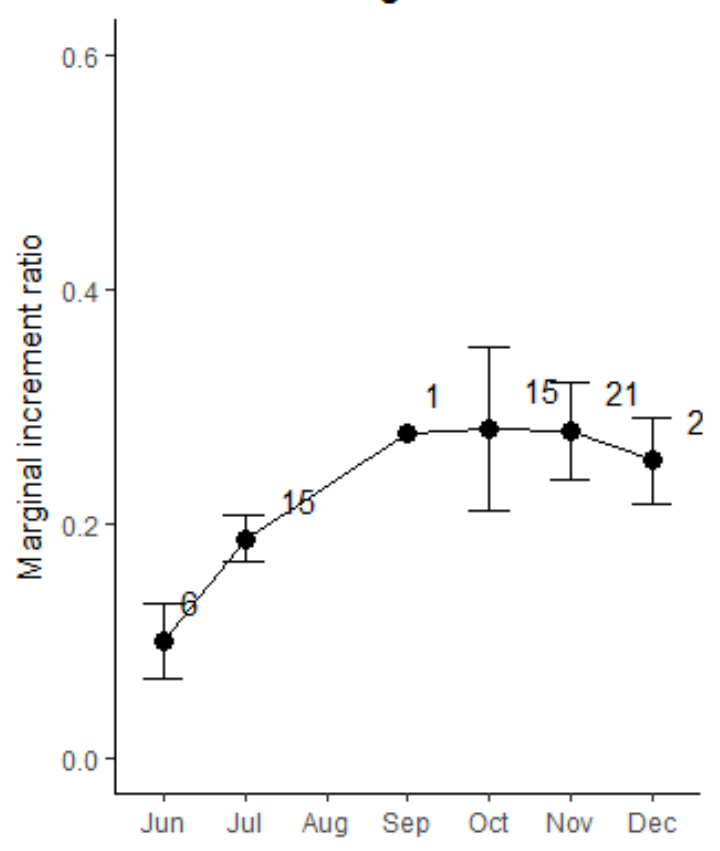

Age 2

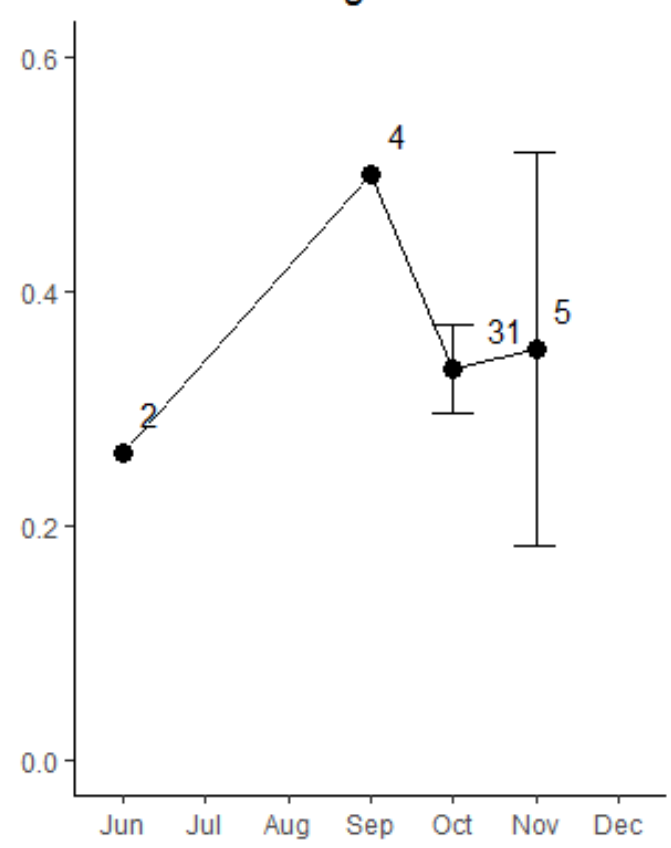

Fig. 5 Marginal increment ratio in relation to month of capture and plotted separately per age class, with error bars and sample numbers per month ( $\mathrm{n}=102$ otoliths). Only three age 3 fish were randomly selected for the MIR analysis. Due to the low numbers these fish were not plotted. 


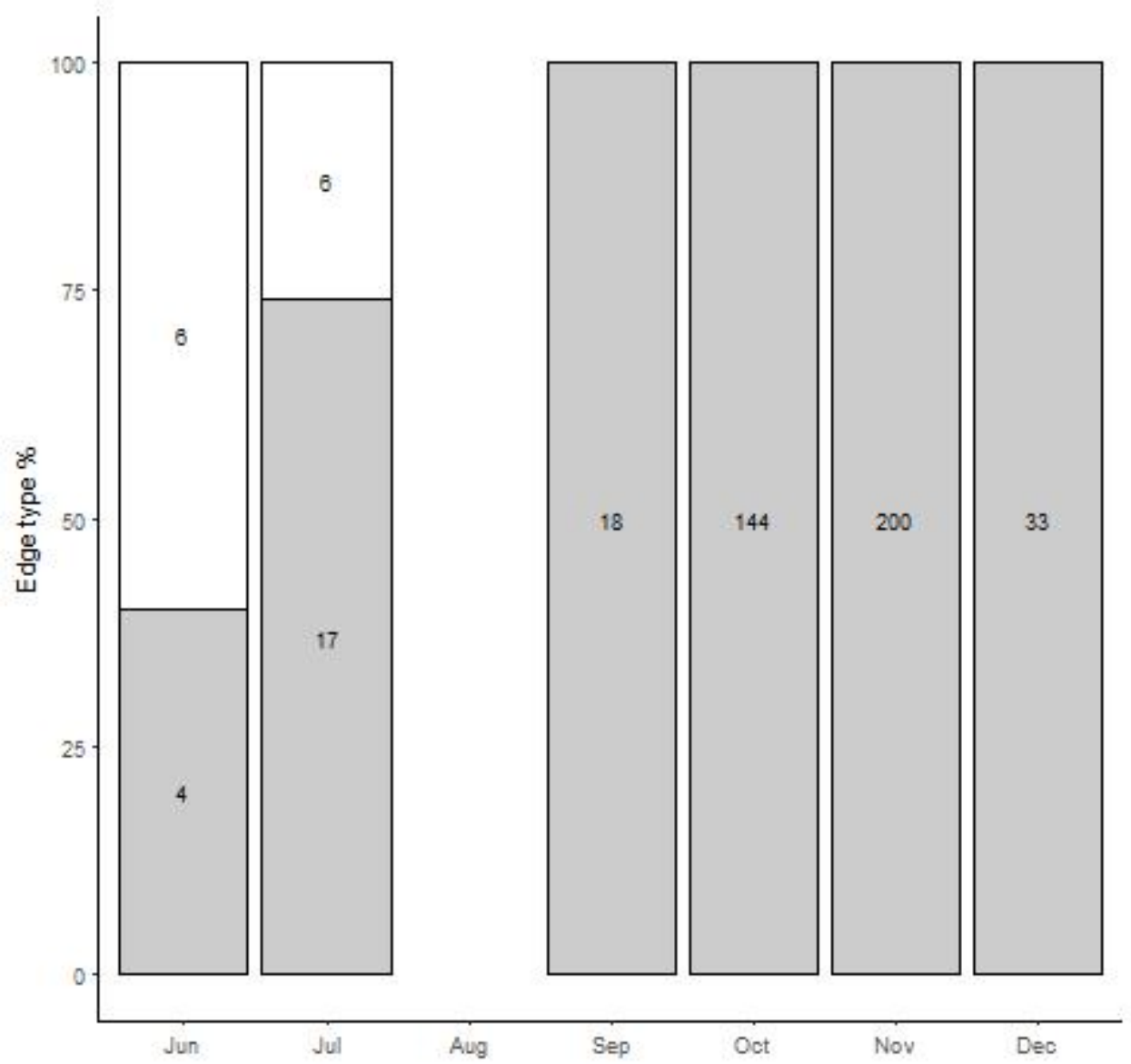

Fig. 6 Visual appearance of the otolith edge as a percentage of the total number of otoliths analysed each month (white, opaque, black, transparent). The proportion of edge type present in the sprat otoliths by month of capture. The sample number within each bar is shown. 


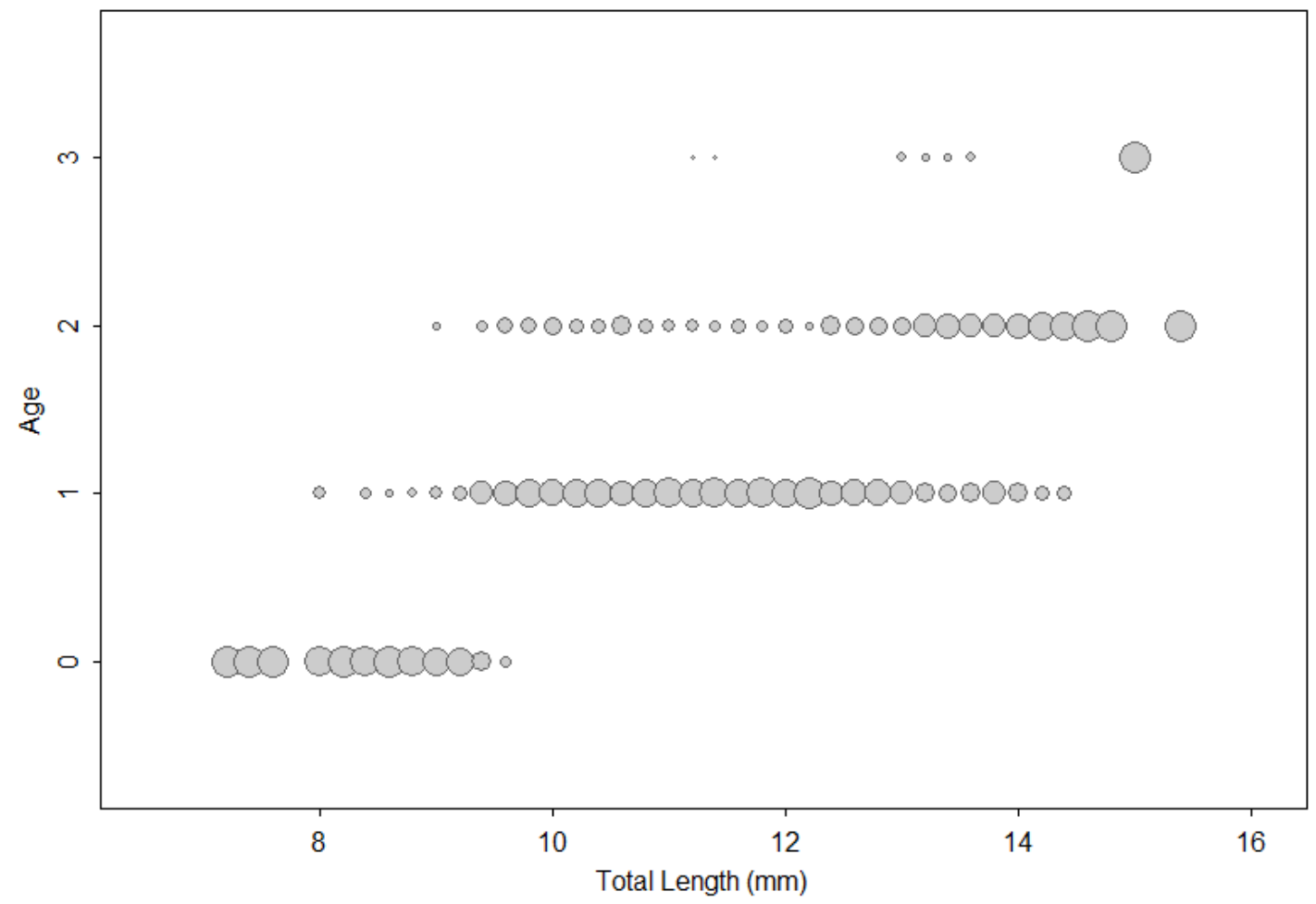

Fig. 7 Observed length at age for sprat in the Celtic Sea ecoregion. The area of the circle is proportional to the proportion of fish in a length interval that area given age. 